\title{
Amount of e-banking fulfillment
}

\author{
Farshad havasi ${ }^{1}$, Fattaneh Alizadeh Meshkany ${ }^{2}$, Reza Hashemi ${ }^{3}$ \\ ${ }^{1}$ Master Student of Business Management, Kermanshah Branch, Islamic Azad University, Kermanshah, Iran \\ ${ }^{2}$ Faculty member Department of Business Management, South Thran Branch, Islamic Azad University, Thran, \\ Iran \\ ${ }^{3}$ Faculty member Department of Science, Razi University, Kermanshah, Iran
}

\begin{abstract}
The comprehensive development of information and communication technology in the recent decades has made human face wonderfulevolution in all aspects of his life. Indeed, this evolution has had undeniable effects on economy general structure and social and cultural parts at the international level. Also, this evolution includes financial and banking services of the current century economy. They are so efficient that they have created some innovations on the kind, quality and quantity of the presented services. Technological revolutions creating high speed and low cost systems of electronic exchanges have seriously evolved financial and banking market structure. Thus this research considers e-banking fulfillmen.
\end{abstract}

Key words: substructure, electronic banking

Submitted Date 02 July 2013

Accepted Date: 07 July 2013

\section{Introduction}

The world is changing at a staggering rate and technology is considered to be the key driver for these changes around us. An analysis of technology and its uses show that it has permeated in almost every aspect of our life. According to Tero et al (2004) many activities are handled electronically due the acceptance of information technology at home as well as at workplace. Internet can be seen as a truly global phenomenon that has made time and distance irrelevant to many transactions. According to Heikki et al. (2002), the transformation from the traditional banking towards e-banking has been a 'leap' change.

The evolution of electronic banking started from the use of automatic teller machines (ATM) and has passed through telephone banking, direct bill payment, electronic fund transfer and the revolutionary online banking. The future of electronic banking according to some is the acceptance of WAP enabled banking and interactiveTV banking (Petrus \& Nelson, 2006). But it has been forecasted that among all the categories, online banking is the future of electronic financial transactions.

Electronic banking provides the facility to the customers to access their accounts and execute

transactions electronically in a very easier way by visiting the bank websites at any time i.e. 24 hours a day, 7 days a week. By using this facility individual and companies are saving a lot of their time and money. Some banks are providing this facility free of cost while some banks have lower the costs for online transactions as compared to real life banking transactions (Karjaluoto et al., 2002, p.261).

E-banking technologies have proliferated in recent years, and the availability of a wide range of products has led to increasing adoption among consumers. These technologies include direct deposit, computer banking, stored value cards, and debit cards (Servon and Kaestner, 2008). Consumers are attracted to these technologies because of convenience, increasing ease of use (Anguelov et al., 2004). E-banking, in particular, has grown at impressive rates. Between 1995 and 2003, e-banking increased eightfold (Hogarth and Anguelov, 2004). Between late 2002 and early 2005, use of online banking increased 47\%, a clear evidence that e-banking isassociated with better household financial management (Smith, 2006).

All businesses, including small and medium scale industries, no matter their geographical locations, are all beneficiaries of e-banking. It encompasses all kinds of commercial transaction that is conducted on an electronic medium, mostly through the internet. E-banking links business to customers no matter their geographical location.

It allows companies to make new business contacts from different global business alliances, test new products and services, and make market research and other enquiries all at a minimal cost both financial and otherwise (Shin, 2008).

E-banking creates unprecedented opportunities for the banks in the ways they organize financial product development, delivery, and marketing via the Internet. While it offers new opportunities to banks, it also poses many challenges such as the innovation of IT applications, the blurring of market boundaries, the breaching of industrial barriers, the entrance of new competitors, and the emergence of new business models (Saatcioglu et al. 2001, Liao and Cheung 2003). Now, the speed and scale of the challenge are rapidly increasing with the pervasiveness of the Internet and the extension of information economy (Holland and Westwood 2001). 
However, to successfully cope with the challenge of the e-banking innovation, the incumbent banks must understand the nature of the change and capability barriers that it presents. Without this understanding, attempts to migrate to e-banking may be doomed to failure. Banks that are equipped with a good grasp of the e-banking phenomenon will be more able to make informed decisions on how to transform them into e-banks and to exploit the e-banking to survive in the new economy(Southard and Siau 2004). Given the e-banking is a financial innovation (Liao and Cheung 2003), the change may render the organizational capabilities of the traditional banks obsolete. From the resource-based view, in such a context, the banks must constantly reconfigure, renew, or gain organizational capabilities and resources to meet the demands of the dynamic environment. Developing core capabilities can help the banks redeploy their resources and renew their competences to sustain competitive advantages and to achieve congruence with the shifting business environment.

Implementation of electronic banking in any country as requires to a different infrastructure that recognizing infrastructure and identifies problems and challenges in during implementation and improvement of electronic banking is appropriate guide in achieving success of Banks. Modern organizations are located in complex global competitive environment that it is due to environmental changes, organizational and technological. The rapid growth of information technology and the internet has changed the nature of work in organizations. Thus the appropriate use of technology in business seems essential factors for survival of organizations in today's competitive environment. Entering information technology and internet to the field of financial transactions, while facilitating this exchange, has greatly reduced the amount of financial costs. So all the world's major banks is looking to enter faster and more serious in the electronic exchange markets and providing services through internet banking to their customers. Electronic banking is defined as perform all matters banks in an electronic environment that customer access to the bank perform a very fast, comfortable, in all day and night, regardless of location and time. On the other hand, banks can offer their services with greater efficiency and lower costs.

\section{Literature review}

E-Banking is more widely used in the last few years, e-commerce has emerged and has developed a high-level business environment that created millions of new job opportunities and increased performance while saving time (Seyed Javadiyan and Sagatchi 2006). E-banking is considered the foundation of e-commerce and number of industries and businesses that are moving toward e-banking is increasing rapidly.

E-banking refers to financial activities that involve use of electronic technology ranging from the now ubiquitous automatic teller machines (ATMs), to other services such as direct deposit, electronic bill payment, electronic funds transfer (EFT), telephone banking, and on-line banking (Lee 2000).

These financial electronic technologies are in differing stages of development. ATMs, a mature e-banking product, have existed for approximately 30 years and have been widely accepted among consumers. Conversely, telephone banking, electronic bill payment, online

banking and mobile banking represent more recent additions to e-banking services.

In a climate of increasing online competition, banks that have chosen to retain extensive branch networks are realigning the roles of staff in these branches and moving towards a relationship-driven sales culture (Durkin, 2007). E-banking has been around for some time in the form of automated teller machine and telephone transactions. More recently, it has been transformed by the internet - a new delivery channel that is fast, convenient, available round the clock, and from whatever the customer's location. E-banking also can increase competition among banks, and allows banks to penetrate new markets and thus expand their geographical reach. Some even see e-banking as an opportunity for countries with underdeveloped financial systems to leapfrog into advanced stages (Gao and Owolabi, 2008). Customer in such countries can access services more easily from banks outside one's own country through wirelesscommunication systems, which are developing more rapidly than traditional 'wired' communication networks (Gao and Owolabi, 2008).

electronic banking is an important and fundamental issue that plays an important role in reaching to electronic government. Generally speaking electronic banking includes all banking services using electronic system by the virtue of safe mediators in a way that physical presence is no longer necessary. The beginning of electronic banking turns back to 1960s when computers were used in banks for the first time. The second round of electronic banking started at late 1970s and it was named automation of the office. Using telecommunication services was also common in this period. The third round started in the middle of 1980 s by connection of customers to accounts. In this round the connection of customers with their accounts, telephone, ATM, etc was used. Finally, fourth period was accompanied by uniting the systems and connecting the customer to all banking operations. The beginning of electronic banking in Iran goes back to 1981-1991. Tejarat bank issued the first bank card in 1991 and after that Sepah bank started to establish 7 ATM stands all over the country. In 1992 Iran joined SWIFT(Society for Worldwide Interbank Financial Telecommunication ) international channel and it was connected to the channel in 1993. 


\section{Different forms of electronic banking}

The terms 'PC banking', 'online banking', 'internet banking', 'telephone banking' or 'mobile banking' refer to a number of ways in which customers can access their banks without having to be physically present at the bank branch. E-banking may be understood as a term that covers all these ways of banking business electronically:

Tele-banking: Tele-banking service is provided by phone. To access an account it is required to dial a particular telephone number and there are several options of services.

- PC-banking: The increasing awareness of the importance of computer literacy has resulted in increasing use of personal computers through the entire world. The term 'PC-banking' is used for banking business transacted from a customer's PC, i.e., customers can use their personal computers at home or at their office to access their accounts for transactions by subscribing to and dialling into the banks' intranet proprietary software system using password.

- Internet banking: Internet banking would free both bankers and customers of the need for proprietary software to carry on with their online banking transactions. Customer behaviour is changing rapidly. Now the financial service is characterized by individuality, independence of time and place and flexibility. These facts represent huge challenges for the financial service providers. So the internet is nowconsidered to be a 'strategic weapon' for them to satisfy the ever-changing customers' demand and innovative business needs.

- Mobile banking (m-banking): A more recent e-banking development is wireless internet applications of banking - sometimes called m-banking. With the combination of internet and mobile phone, a new service (mobile data service) is thus enabled and the first such wireless internet commercial transaction was performed by the banking industry (Barnes and Corbitt, 2003).

E-Banking in the scope of this study will generally refer to the combination of Online Banking, Mobile Banking and ATMs. These rather new channels of banking will be briefly overviewed below.

\section{ATMs}

In the late 1980s, Iranian banks felt the need to automate banking processes and started to computerize their banking tasks (Reporter 2007). At first there was only 7 - 10 ATMs in Tehran and Sepah bank was the premier to issue electronic cards that could be used for very limited number of banking tasks in ATMs. Melli bank was the second to come up with electronic cards with more functionality and soon all banks were installing ATMs in their branches and issuing cards (Kazemi Dinan 2007). The major problem was that none of these banks were integrated with another one and each bank was an isolated island incapable of performing transactions with another one. Each bank had created an e-banking system based on a network that was notconnected to other bank networks. Saderat bank had the Sepehr system, Keshavarzi bank created the Mehr system. Melli bank came up with the Siba system and Melat bank introduced the Jam network. Banks were advertising their ebanking systems and were encouraging users to use their system where none of them had a significant advantage over the other.

In 2002, a network was designed to connect Melli bank with Shahrvand superstore POSs, later that year the idea was generalized and a superhighway of banking transactions that banks could use to integrate their banking services was designed. The network was called Shetab and was tested with integration of 2 major specialized banks of Toseé saderat and Keshavarzi and one commercial bank Saderat. In 2003 Saman bank joined the network to be the first private bank integrated with governmental banks and in 2004 Melli bank as the Iran's biggest bank with the largest number of branches joined the network (Seyed Javadiyan and Sagatchi 2006). Today many governmental and private banks have joined the network and Shetab has become the infrastructure network for electronic banking (Kazemi Dinan 2007).

According to the Iran ministry of ICT 14,000 branches out of 15,600 are now connected to national banking network in Iran. In 2007 there were 8,440 ATMs and 244,000 POS with a total number of 27 million electronic cards were present in the whole country and it is expected to have 30,000 ATMs and 900,000 POSs installed and 75 million electronic cards provided for the customers until 2010 (Reporter 2007).

\section{Internet Banking}

Technological advances have changed the world radically. Emergence of IT has altered the manner in which individuals conduct their business affairs. The World Wide Web (WWW)

had a significant impact, since it started facilitating the Internet to both individuals and businesses (E.AbuShanab 2007).

World Wide Web users have been increasing exponentially since its introduction in the early 1990s. According to the numbers published by World Internet Stats, there are approximately 1,596 million users worldwide which in year 2000 was only 360 million users.

The average penetration rate is 23.8 percent and the users growth rate is approximately 342.2 
percent. (Miniwatts Marketing Group 2009).

The projected users growth rate in the middle east is much higher, in year 2000, there were only 3 million users in the middle east which is approximately 46million users in 2009 therefore middle east has growth rate of 1,296.2 percent (Miniwatts Marketing Group 2009).

Iran in the Middle East second to Syria has the highest growth rate. Based on the numbers provided by World Internet Stats Iran in year 2000 had only 250,000 internet users where in the year 2009 with a growth rate of 9,100 percent Iran has approximately 23 million internet

users. (Miniwatts Marketing Group 2009).

Internet in Iran was first introduced in 1993 (Iran Ministry of ICT 2005) and it was for academic use only, since then It has grown rapidly and now with the penetration rate of 34.9 percent Iran has more than $50 \%$ share in middle east internet users (Miniwatts Marketing Group 2008). Such a tremendous and rapid growth in the number of internet users, have created new opportunities for many businesses and has introduced new horizons for many industries. Like many other technologies internet was first used to have an edge and to gain competitive advantage but soon being online became a competitive necessity and many industries and businesses are feeling the pressure and moving toward online presence. Banking was one of the few industries that have witnessed a significant influence of WWW technology. Over the past few years the banking industry has invested substantial resources in bringing Information Technology and online services in particular to consumers. The banking industry has implemented new and technology-based services on the internet called -online banking

In the organizational scope, online banking makes simultaneous service to numerous customers with various needs possible. Anking industry intends to make banking easier and more convenient for users when compared to traditional systems and services. (Meuter, et al. 2000).

-Online banking assists banks in their transition from multiple locations to a lucrative and

global marketplace (Giannakoudi 1999). What is appealing for banks to move toward onine

banking is the benefit that they gain by decreasing the personnel costs and also technology

driven costs that makes a huge difference in comparison to the traditional bricks-and-mortar

banking (Sarel and Marmorstein 2002).

According to Seyed Javadiyan and Sagatchi, there are three levels of online banking services available for customers: (Seyed Javadiyan and Sagatchi 2006).

-Information level: This is the most basic level in online banking. Website is used only to share information about the services offered by the bank that also includes news regarding new events and general news regarding the bank.

Connection level: slightly more advances than the basic level, full duplex connection between the bank and the customer is made possible. This interactive system is not free of risks and therefore security systems are considered to ensure privacy is not violated and data intergrity remains intact.

- $\square$ Transaction level: This is the most sophisticated online banking level in which transactions are also possible and almost all the traditional banking services are available

through the internet which also comes with greater risks that requires advanced security systems.

In the Beginning online banking systems in Iran were providing mostly information and connection level services in which it was possible to view account status but money transfer and opening and managing accounts were not possible. Saman Bank was the pioneer and among the very few private banks to implement online banking technology (Seyed Javadiyan and Sagatchi 2006). Today most of the banking services are accessible through online banking systems but one still needs to open a primary account in a physical branch and intrabank services are still not mature (Reporter 2007).

\section{Mobile Banking}

Over the last few years, along with the internet, the mobile and wireless technologies has been evolved and mobile banking was born. Mobile banking referes to all the services offered by a bank that are made available on a mobile device such as mobile phones, hand helds and pocket pcs, some of these services are performing balance checks, account transactions, payments etc.

Security of financial transactions, being executed from some remote location and transmission of financial information over the air, are the most complicated challenges that need to be addressed jointly by mobile application developers, wireless network service providers and the banks' IT departments.

According to a new report from Celent, US Mobile Banking: Beyond the Buzz, - Mobile banking is here to stay and will grow significantly faster than online banking\| (Celent, LLC 2007) approximately 46 million households in United states currently bank online. By the end of 2010, a total of $35 \%$ of online banking households has gone mobile.

Addition of new features and possibilities will bring certain advantages for mobile banking to further differentiate the technologies and be more appealing for internet banking users. (Celent, LLC 2007) By 
observing this growth trend, it is predicted to see growth in mobile financial information systems, fund transfer, bill-payment, administration of accounts and customer service solutions.

Prediction of new technology adoption rates has always been challenging, in this case it is possible to use online banking adoption rate as a measuring stick. U.S. consumers currently

prefer PCs rather than mobile devices for banking

Many Governmental banks such as Saderat, Melat, Refah, Melli, Sepah, Maskan and some private banks, Parsian, Pasargad, Sarmaye, Saman, are provising Mobile banking services.

Some of these banks like Melat and saderat offer mobile baning services only to their own sustomers and some like Parsiyan also offer services for every Shetab account holder which includes majority of the Iranian banks. The greatest challenge here, like any other bank in the world is the lack of technological standard for mobile banking. The best choice is to make software to support multiple platforms and many Iranian banks are using Java that is supported by many mobile phones today. Internet on mobile phones using GPRS, EDGE is also new in Iran before which banks had to base their mobile banking services to short message service with very limited functionality. Iranian Mobile banking is almost 5 years old now and it offers bankingservices like Balance checking and recent transaction history, Fund Transfer, Bill Payment, mobile phone credit charging, etc.

\section{Importance of E-banking in Iran}

Internet banking became very attractive to customers and lots of banks because the technology is being accepted by them and they can now understand and have information about the complex products. Nowadays banks are also facing a lot of competition and need a high market share and provide better services to its customers so that they can attract the new customers and old customers do not try to leave them.

While using the online banking there are a lot of advantages that customers are getting.

Online banking provides benefits to users and also to the banks. Users can use online services dependent on convenience which is independent of time and place constraints. Online banking helps banks to reduce transaction costs and cost of operation in the form of reducing staff and physical branches. In developing countries like Iran, e-banking initiatives are taken to utilize the technological benefits that can be harvest along with many other ereadiness measures being taken. Iran has been among the late entrants into e-banking.

In Iran, high technological diffusion have enforced the fundamental changes in the financial industry, new considerable business plans have open the new ways for doing business, launching electronic business and use of Information and technology for the development of better internal controls and more complicated risk management systems, better and superior convenient customer services (Akhtar, 2006).

Hence it is critical that the financial industry of Iran adopts an appropriate organizational model that supports business process re-engineering and customer centric approach to create cost efficiencies and economies of scale to exploit technology (Akhtar, 2006). Inter-connectivity of switches and establish networks of ATMs makes it possible to use ATM and electronic banking services which is gaining currency. Services offered by ATMs and their better outreach will enhance the customer base and provides more alternatives to the customers which will open up new avenues for them. Smaller banks will be able to vie with large banks to retain their market presence by using technology more efficiently.

\section{Infrastructure}

According to Pauline (2001) the availability of sufficient infrastructure has been measured and he found that it is a significant predictor of ebanking success and failure. The infrastructure plays a very vital role and in order to establish, the infrastructure the internet infrastructure is very important and some serious steps should be taken for the effective growth of internet. If the current infrastructure is compared with the 5 years before then we can see that there a lot of changes that have been conducted by the Government of Iran an attempt to improve infrastructure and it was mainly done after privatizing the banks of Iran. Recently the infrastructure has been increased like the payment system, ATM machines and due to this reasons the transactions that have been conducted from ATM cards have been increased

High cost of access to the devices that give access over the networks to purchase is relatively very high like costly internet connection, wireless local loop infrastructure. Merchants don't want to spend money in terminals which is rejecting the consumers to use electronic banking system Analysis reveal that Proper Infrastructure and Quality of Service are the most important factors for running the E-banking.

\section{Challenges Of E-Banking}

-Operational challenge. The reliance on new technology to provide services makes security and system availability the central operational risk of electronic banking. Security threats can come from inside or outside the system, so banking regulators and supervisors must ensure that banks have appropriate practices in place to guarantee the confidentiality of data, as well as the integrity of the system and the data. 
- Reputational challenge. Breaches of security and disruptions to the system's availability can damage a bank's reputation.

- Security challenge.

Internet banks collect and keep some very important personal information from each client. As Internet technology advances, so does the ability of criminals to hack into an Internet bank

and steal important client information, according to financial expert Steve Ellis, writing on the Computer World website. Internet banks must constantly update security measures andstay updated on the latest viruses and hacker tools in order to protect client information.

Although there are many associated benefits from adopting online banking services but there are many0reasons which obstruct theOrecognition of electronic0banking. In case of Iran, many private0banks still using old banking system and don't have access to take advantage from electronic banking facilities. observed the following reasons which may be considered as hindrance factors for electronic banking. These hindrance factors includes lack of internet facilities with customer, learning how to interact with bank website, internet cost, technical issues related with personal computer and technology awareness. Similarly some user feels confident with traditional banking system as adopting new e-banking services leads them to learn new technologies like computer, making internet connection etc. According to Akinci et al. (2004), security issues are one of the most important barriers for electronic banking users.

\section{Conclusions}

Analysis indicate that Customer acceptance to online banking is slow because of different factors. These factors includes insecure transaction, slow speed of internet, high internet rates, low computer literacy rate and lo Analysis indicate that most of the users have concern about their data privacy and security. Bank has to take initiative to increase customer orientation by educating them about new technology and security issues. In order to improve customer satisfaction, government has to provide basic infrastructure required to access online banking services. Most of the government offices still using the manual system and lag behind to adopt computer technology. New technology not only saves time but also efficiency. Government has to rethink about existing policies to improve and make situation favorable for prospective customers.

\section{Suggestions}

- Regulatory authorities like CBN (Central Bank of Iran) must stipulate standards for the banks to follow to avoid making Iran Banking Sector a dumping ground for the outdated technological infrastructures. Training and Manpower development is another major problem militating against the growth of e-commerce in the country. Government must make right IT policy by ensuring that Computer, Communication equipments and other IT infrastructures to a large extent are manufactures in the country so that our people can acquire first hand necessary skills. Government Policy that will guide against Money laundering, fraud and Security risks posed by net banking is inevitable.

- In order to clarify organization purpose and route in the field of electronic banking, common meetings will be formed between staff and executive directors so that they achieve a common perspective in this field. On the other hand should effort in meetings make decisions of staff managers in the field of electronic banking have also attended executives' managers and considered their idea and their full participation attract in the implementation of decisions and processes.

- In vision document should specified the objectives, strategies and programs and priorities and administrative procedures of the work be clear completely and comprehensive, This document shouldbe characterized orientation and move of strategic towards electronic banking in domestic and international activities until based on it be developed operational planning for implementation.

- Development of qualitative and quantitative specialist force be placed on the agenda. Of course, through retraining of existing forces and adopt appropriate methods to attract and retain specialists in the field of electronic banking can be overcome over the problem of shortage specialist force in this field.

- Providing financial cost in basic systems and electronic banking software, computer hardware and infrastructure requirements for banks which is considered a type of investment.

- Conducting advertising costs and information about education and culture encourage and promote the use of electronic banking tools to customers, promote brand to organization various ways in public media, internet, bill boards and advertising boards.

\section{References}

[1]. Anguelov, C.E., Marianne, A.H. and Hogarth, J.M. (2004) 'U.S. consumers and electronic banking: 1995-2003', Federal Reserve Bulletin, Vol. 90, Winter, pp.1-18.

[2]. banking in Finland", International Journal of Bank Marketing; Volume: 20 Issue: 6; 2002 Research paper.

[3]. banking on the financial behavior of lower-income bank customers', Journal of Consumer 
[4]. banking: an extension of the technology acceptance model"(2004)Internet Research; Volume: 14 Issue: 3; Research paper

[5]. Barnes, S.J. and Corbitt, B. (2003) Int. J. of Mobile Communications, Vol. 1, No. 3, pp.273-288.

[6]. Celent, LLC. US Mobile Banking: Beyond the Buzz . May 17, 2007.

[7]. communication." Journal of Financial ServicesMarketing 6, no. 3 (2002): 254-267.

[8]. Data Monitor. E-banking technology in europe. 2001. http://www.imi.ir/tadbir/tadbir-170/article- 170/4.asp (accessed April 29, 2009).

[9]. Durkin, M. (2007) 'On the role of bank staff in online customer purchase', Marketing Intelligence \& Planning Journal, Vol. 25, No. 1, pp.82-97.

[10]. E.AbuShanab, J.M.Pearson. "Internet Banking in Jordan, The unified Theory of Acceptance and Use of Technology (UTAUT) perspective." Journal of Systems and Information Finance, Vol. 2, No. 2, pp.180-196.

[11]. Electronic Finance, Vol. 2, No. 3, pp.284-299.

[12]. Gao, P. and Owolabi, O. (2008) 'Consumer adoption of internet banking in Nigeria', Int. J.

[13]. Giannakoudi, S. "Internet banking: The digital voyage of banking and money in cyberspace."

[14]. Heikki Karjaluoto, Minna Mattila, Tapio Pento (2002), "Factors underlying attitude formation towards online.

[15]. Hogarth, J.M. and Anguelov, C.E. (2004) 'Are families who use e-banking better financial

[16]. Holland, C.P. and J.B. Westwood, "Product-Market and Technology Strategies in Banking,"(2001) Communications of the ACM, Vol. 44, No. 5: 53-57.

[17]. http://www.internetworldstats.com/stats5.htm (accessed April 25, 2009).

[18]. Information \& Communications Technology law 8, no. 3 (1999): 1-40. Int. J. Electronic Finance, Vol. 1, No. 1, pp.5-17.

[19]. Iran Ministry of ICT. Internet and its current status in Iran. 2005. http://www.ict.gov.ir/articlefa- 1.html (accessed April 29, 2009).

[20]. Karjaluoto, H., Mattila, M. \& Pento, T. (2002). Electronic banking in Finland -consumer beliefs and reactions to a new delivery channel. Journal of Financial Services Marketing 6 (4), forthcoming.

[21]. Karjaluoto, H., Mattila, M. and Pento, T. (2002), "Factors underlying attitude formation towards online banking in Finland", International Journal of Bank Marketing, ISSN 0265-2323, Vol. 20 No. 6, pp. 261-272.

[22]. Kazemi Dinan, G. e-banking in Iran. 2007. http://kazemidinan.blogfa.com/post-1.aspx (accessed April 28, 2009).

[23]. Keramati, A. and Hadjiha, B. and Saremi, M.S. (2008), "A Proposal Framework for Adoption of Electronic Payment Services by Iranian Customers", the IEEE international conference on industrial informatics (INDIN 2008).

[24]. Lee, E-J. "Consumer adoption of technological innovations: A case of electronic banking

[25]. Liao, Z. and Cheung, M.T. (2002), "Internet-based e-banking and consumer attitudes: an empirical study", Information \& Management, Vol. 39 No. 4, pp. 283-95.

[26]. managers?', Financial Counseling and Planning, Vol. 15, No. 2, pp.61-78.

[27]. Meuter, M.L, A.L Ostrom, R.I Roundtree, and M.J Bittner.( 2008)"Self-service technologies: Understanding customer satisfaction with technology-based service encounters." Journal

[28]. Miniwatts Marketing Group(2000). Internet Usage in the Middle East. December 31 of Marketing 54, no. 3: 50-65.

[29]. Pauline, R. (2001). Electronic commerce adoption in Australia and New Zealand. Malaysian Journal of Computer Science, 14 (1), pp. 1-8. June.

[30]. Porter, W.T (2005), User-Centered Design and Marketing: Online Customer Value, Published in 'Contemporary Research n E-Marketing, Volume: 2, by Idea Group Publishing.

[31]. Saatcioglu, K.,J. Stallaert, and A.B.( 2001). Whinston, "Design of a Financial Portal," Communications of the ACM, Vol. 44, No. 5: 33-38.

[32]. Sarel, D.,, and H Marmorstein. "Migrating customers to new distribution channels:The role of

[33]. Servon, L.J. and Kaestner, R. (2008) 'Consumer financial literacy and the impact of online

[34]. Seyed Javadiyan, R, and M Sagatchi(2006). "Internet banking and its histoy of changes in Iran.".

[35]. Shin, K.H. (2008) 'Is e-banking a competitive weapon? A causal analysis', Int. J. Electronic

[36]. Smith, A.D. (2006) 'Exploring security and comfort issues associated with online banking',

[37]. technologies." (Doctoral dissertation, The University of Tennessee, 2000). AAT 9996366., 2000. Technology 9, no. No 1 (2007): 78-97.

[38]. Tero Pikkarainen, Kari Pikkarainen, Heikki Karjaluoto, Seppo Pahnila (2004), "Consumer acceptance of online

[39]. technologies." (Doctoral dissertation, The University of Tennessee, 2000). AAT 9996366., 2000. Technology 9, no. No 1 (2007): 78-97. 